\title{
Awareness and Practice of Health Care Providers towards Communicable Disease Surveillance in Assuit University Hospitals - Egypt
}

\author{
${ }^{1}$ Faten M. Rabie, ${ }^{2}$ Saeed S. Abduljalil Soliman, ${ }^{3}$ Amany H. Abdulmoean \\ ${ }^{1}$ Public health and community medicine Faculty of Medicine- Assiut University. ${ }^{2}$ Family \\ Medicine Faculty of Medicine -Cairo University. ${ }^{3}$ Family medicine Al-Ghanaym city- \\ Ministry of Health
}

Received: February, 2018 Accepted: May, 2018

\section{Abstract}

Introduction: Communicable disease control is announced as one of the most important health issues internationally. Poor disease surveillance is a main cause for increased mortality and morbidity of communicable diseases. The main purpose of public health surveillance is to provide actionable health information to public health staff, governmental leaders and the public. Lack of knowledge, poor attitude and practice are identifiable causes of noncompliance to surveillance system requirements among health care providers. Objective: This study aims to assess the knowledge, attitude and practices of Assuit university health care providers regarding the reporting of communicable diseases. Method: Across sectional study was conducted on 347 physician and 73 head-nurses at Assuit University Hospitals. Interview questionnaire covering personal and work data, knowledge, attitude and practice was used. Results: only $40 \%$ of participants have knowledge about the presence of communicable disease surveillance system and unit. Regarding knowledge about the functions of the surveillance; the most known functions were: application of collected data for disease prevention and control and dissemination to allow action. Small percentage of participants didn't know any function of the system. Conclusion: Less than a quarter of the participants have a good knowledge of the surveillance of communicable diseases. Most (three quarters) of the participants have a positive attitude about communicable diseases surveillance. Head nurses have slightly more adequate practice than physicians. The main reasons for nonreporting were: lack of knowledge about how or to whom to report or which diseases to report and time constraint.

Keywords: Awareness, Health, Provider, Communicable, surveillance

Corresponding author: Amany H. Abdulmoean dramany2016@yahoo.com

\section{Introduction}

Communicable disease control is announced as one of the most important health issues internationally ${ }^{1}$ and is still the leading cause of morbidity, death and disability in African countries. ${ }^{2}$

Surveillance for infectious diseases is an important factor in providing effective public health disease control and prevention services ${ }^{3}$ as it is a key in public health decision- making and practice. Poor disease surveillance is a main cause for increased mortality and morbidity of communicable diseases. ${ }^{4}$ Until 1950 , the term 'surveillance' was limited to public health practice to monitoring contacts of persons with serious communicable diseases such as smallpox, in order to detect early symptoms so rapid isolation 
could be done and this is often called "epidemiologic surveillance "or public health surveillance. ${ }^{5}$ It has been redefined in 1986 by the Centre of disease control (CDC) to include the ongoing systematic collection, analysis, and interpretation of health data essential to the planning, implementation, and evaluation of public health practice, closely integrated with the timely dissemination of these data to those who need to know. ${ }^{6}$ This definition has been emphasized by World Health Organization in 2012. ${ }^{7}$

Surveillance can be passive, active, sentinel or syndromic. Passive surveillance or case reporting has many limitations and weaknesses over the active surveillance in which there is effort to collect data and confirm diagnoses to ensure more comprehensive reports(8). Active surveillance gives more complete and dependable information about a disease and may be required in particular surveillance situations, however it is often short-term and usually requires more skilled and well-supervised persons with adequate management as well as financial support than passive surveillance. ${ }^{9}$

The seven core activities of surveillance system are (1) Case detection (identifying cases and outbreaks) through the official health system, private health systems or community structures. (2) Registration is the procedure of recording the documented cases. This requires an identical register to record the minimal data elements on diseases and targeted conditions. (3) Confirmation refers to the epidemiological and laboratory capacity. The ability to confirm case is improved by strengthening referral systems and partnerships. (4) Reporting is the process by which surveillance data are sent through the surveillance system from the generation point. (5) Analysis and interpretation preparing and occasionally updating graphs, tables and charts to describe time, person and location of reported diseases and conditions, recognition of atypical trends or patterns or the exceeding of a threshold value, discussing possible public health action, interpreting results. (6) Response includes case managing, contact tracing, infection control measures, immunization activities, improvement of preventive and control procedures. (7) Feedback; It is a core function of all surveillance systems. A Good feedback can be maintained through decisionmaking visits, newsletter and bulletins. It is possible to keep an eye on the feedback by the different levels of surveillance and evaluating the quality of feedback provided, and the implementation of follow-up action. ${ }^{10}$

In Egypt, National Electronic Disease Surveillance System (NEDSS) evolved from activities supported by the Ministry of Health and population (MOHP), WHO and United States (US) government in the late 1990s(11). There are two groups of communicable disease under surveillance in Egypt according to the handbook for the definition of communicable diseases Reporting National surveillance program 2017 by Central Epidemiology and Disease Surveillance; Group A: immediate reported diseases and Group B weekly reported diseases.

Health care providers are corner stone of communicable disease surveillance. ${ }^{12}$ Measuring their knowledge, attitude, and practice (KAP) regarding surveillance system is crucial as the most common reason for doctors not complying with reporting requirements was lack of knowledge of the reporting requirements, followed by a negative attitude to reporting, misunderstanding that may result from a lack of knowledge of the reporting system, and inadequate reward for reporting or punishment for not reporting. ${ }^{3}$ 
To our knowledge, research on knowledge, attitude and practice about the surveillance system of communicable diseases in Egypt is lacking. Therefore, we carried out this study to assess the knowledge, attitude and practices of Assuit university health care providers regarding the reporting of communicable diseases, and to identify the determinants of knowledge, attitude and practice (KAP) gap among the studied health care providers.

This study aims to help the planners at all levels of the health systems to develop a general framework for a vision, strategies and routine operational plans for strengthening the surveillance system and response.

Study Objectives: To assess knowledge, attitude and practices of Assuit university health care providers regarding surveillance of communicable diseases and to identify the determinants of KAP gap among the studied health care providers.

\section{Method}

This is a cross sectional study conducted on 420 health care providers (at clinical departments of Assuit University Hospitals, through the period December 2017 to May 2018.

Assiut University Hospitals (AUHs) has taken the initiative to work in close collaboration with MOHP to be the first university to have a communicable diseases surveillance system that is part of the NEDSS for communicable diseases. Assuit University Hospitals (AUHs) are located in the Capital city of Assuit governorate, $400 \mathrm{Km}$ south of Cairo, Egypt's Capital. AUH is considered one of the largest and oldest University hospitals in Egypt and is composed of 8 hospitals:
Main Hospital, Children Hospital, Women Health Hospital, Om Elksor Hospital, Al Rajhi Liver Hospital, Psychiatric and Neurological Hospital, Urology and Kidney Surgery Hospital and Orman University Hospital for Cardiology.

Health care providers (physicians and head nurses) working in clinical specialties related to infectious diseases were included for this study. Interns (pre-graduation training doctors and nurses) were excluded.

Sampling Method:

Using Epi-Info version 7 software, with anticipated frequency of good KAP of $50 \%$ with $95 \%$ confidence interval and power $80 \%$ the minimum required sample size was $384,10 \%$ were added to anticipate missing data so the sample size was raised to 420 . The chosen clinical departments had total 786 health care provider $650(82.7 \%)$ physicians and 136 $(17.3 \%)$ head nurses. This ratio of physicians to head nurses was maintained in sample selection (420 totals, 347 $(82.7 \%)$ physicians and $73(17.3 \%)$ head nurses.

Research approvals: The study protocol was approved by the Ethical Committee of Faculty of Medicine, Assuit University. Approval of AUHs Management was also taken prior to the research.

Participants were informed about the objectives, methods, and possible impact of the study and an oral consent was obtained.

\section{Data collection tools and techniques:}

An interviewing English language questionnaire was developed covering personal data as age, sex, position, years of pracice. As well as knowledge about the 
Table 1. Awareness of presence of communicable disease surveillance and its main functions and process among health care providers in Assuit university Hospitals ( $(n=420)$

\begin{tabular}{|c|c|c|}
\hline Questions & No & $\%$ \\
\hline $\begin{array}{l}\text { Awareness of presence of communicable disease surveillance system in } \\
\text { AUHs }\end{array}$ & 168 & 40.0 \\
\hline \multicolumn{3}{|l|}{ Awareness of main functions of the disease surveillance system* } \\
\hline Systematic collection of disease information & 152.0 & 36.2 \\
\hline Dissemination to allow action (in outbreaks) & 206.0 & 49.0 \\
\hline Application of collected data for disease prevention \& control & 259.0 & 61.7 \\
\hline Analysis of disease information & 80.0 & 19.0 \\
\hline Don’t know & 64.0 & 15.2 \\
\hline \multicolumn{3}{|l|}{ Correctly know time for disease reporting } \\
\hline Hepatitis & 149 & 35.5 \\
\hline Meningitis & 38 & 9.0 \\
\hline Avian Flu & 224 & 53.3 \\
\hline human immunodeficiency virus & 202 & 48.1 \\
\hline Tuberculosis & 18 & 4.3 \\
\hline Acute food poisoning & 17 & 4.0 \\
\hline \multicolumn{3}{|l|}{ Knowing who is responsible for current reporting*: } \\
\hline Doctors & 167 & 39.8 \\
\hline Nurses & 90 & 21.4 \\
\hline Others & 17 & 4.0 \\
\hline Don't know & 181 & 43.1 \\
\hline \multicolumn{3}{|l|}{ Knowledge about the reporting method*: } \\
\hline Telephone & 53 & 12.6 \\
\hline Internet & 2 & 0.5 \\
\hline Records & 205 & 48.8 \\
\hline Don't know & 205 & 48.8 \\
\hline \multicolumn{3}{|l|}{ Knowledge about current availability of notification records**: } \\
\hline Yes & 117 & 57.1 \\
\hline No & 9 & 4.4 \\
\hline Don't know & 79 & 38.5 \\
\hline \multicolumn{3}{|l|}{ Knowledge about regularity in supply of notification records**: } \\
\hline Always & 65 & 31.7 \\
\hline Occasionally & 89 & 43.4 \\
\hline Usually out of stock & 2 & 1.0 \\
\hline Don't know & 49 & 23.9 \\
\hline
\end{tabular}


Table 2. Attitude of the participants regarding communicable diseases' surveillance system in Assuit University Hospitals $(n=420)$

\section{Questions:}

\begin{tabular}{cccc}
\multicolumn{2}{c}{ Yes* } & \multicolumn{2}{c}{ No } \\
\hline No. $\%$ & No. & $\%$ \\
\hline
\end{tabular}

a. Reporting communicable diseases is one of the public health responsibilities of the health care providers?

$390 \quad 92.9 \quad 30 \quad 7.1$

\begin{tabular}{lllll}
\hline b. If there is an easy method to report, will you report? & 367 & 87.4 & 53 & 12.6 \\
\hline $\begin{array}{l}\text { c. } \quad \text { Communicable disease reporting is helpful to the safety of your } \\
\text { practice? }\end{array}$ & 373 & 88.8 & 47 & 11.2 \\
\hline d. Communicable disease reporting is important to improve health? & 366 & 87.1 & 54 & 12.9 \\
\hline $\begin{array}{l}\text { e. Punishment for not reporting will increase the willingness to } \\
\text { report? }\end{array}$ & 137 & 32.6 & 283 & 67.4 \\
\hline f. A good reward system will increase the willingness to report? & 303 & 72.1 & 117 & 27.9 \\
\hline g. Need to participate in training course on surveillance system? & 191 & 45.5 & 229 & 54.5 \\
\hline
\end{tabular}

*Yes= Positive attitude. communicable disease surveillance system in AUHs: awareness of the Surveillance unit in the hospital, function of surveillanc and attitude about the communicable disease surveillance system in AUHs: importance of communicable disease reporting to improve health, attitude about the communicable disease surveillance system in general and practice of the health care providers towards communicable diseases surveillance system: diagnosing and reporting of communicable diseases, frequency of reporting, als reasons of not reporting and suggestions to improve the health care providers' compliance about the communicable diseases surveillance reporting were covered.

\section{Statistical Analysis:}

Data were coded and entered using the Statistical Package for the Social Sciences (IBM SPSS Statistics 21) software. Data were summarized using number and percent for qualitative variables, mean and SD for quantitative variables which are normally distributed. Median and interquartile range (IQR) were used for quantitative variables which are not normally distributed. Comparisons between groups were done using the chisquare test. Mann-Whitney test was used for quantitative data comparisons. $\mathrm{P}$ value $\leq 0.05$ was considered as statistically significant.

Knowledge (K), Attitude (A) and practice (P) were calculated by scoring right question responce by one and wrong response by zero, $60 \%$ or more right responces in every section was considered good.

\section{Results}

Four Hundred and twenty (420) health care providers were included in this study. Resident-doctors were the largest portion of participants $(157,37.5 \%)$ followed by assistant lectures $(110,26.2 \%)$ followed by consultants $(80,19 \%)$ and head nurses $(73$, $17.4 \%)$. The mean \pm SD age was $32 \pm 6.5$ years, Participants less than 30 years of age were $45 \%$ of the sample, with mean \pm SD years of practice of $8.3 \pm 6.5$.

More than half of participants were from children's hospital (28\%) and internal medicine $(20 \%)$, followed by equal percentage $(15 \%)$ of participants from women hospital and clinical pathology departments, participants from chest 
Table 3. Practice of the participants surveillance system in AUHs 2018. regarding communicable diseases'

\begin{tabular}{|c|c|c|}
\hline Questions & No. $(n=420)$ & $\%$ \\
\hline Ever diagnosed notified diseases: * & 323 & 93.1 \\
\hline Ever reported notified diseases: & 181 & 43.1 \\
\hline Reported once & 50 & 27.6 \\
\hline Reported twice & 20 & 11.0 \\
\hline Reported three times & 24 & 13.3 \\
\hline Reported more than three times & 87 & 48.1 \\
\hline Always complete patient registers: & 338 & 80.5 \\
\hline $\begin{array}{l}\text { Ever attended training course about } \\
\text { communicable disease surveillance: }\end{array}$ & 45 & 10.7 \\
\hline
\end{tabular}

*Only for physicians $(n=347)$

and tropical medicine departments were nearly equal also at $10.5 \%$ and $11 \%$ respectively. Of all participants, only $40 \%$ know about the presence of communicable disease surveillance system and unit. Regarding knowledge about the functions of the surveillance; the most known functions were: application of collected data for disease prevention and control and dissemination to allow action. Small percentage of participants didn't know any function of the system. Regarding timing and process of disease reporting, as shown in Table 1, around half of participants know the proper timing for reporting of human immunodeficiency virus and avian flu, and only one third know the proper reporting timing for hepatitis, very few participants know proper timing for acute food poisoning and meningitis. Also, half of them didn't know who is responsible about current reporting and what current reporting methods in their department.

The attitude of AUH health care providers regarding communicable diseases surveillance presented in Table 2 shows that $93 \%$ of participants agreed that reporting of communicable diseases is one of the responsibilities of healthcare providers. Most of the participants see that reporting is helpful to the safety of their practice and it is important to improve health. Most participants also will report notified diseases if there is an easy method to report. In the practice part of the survey Table 3 shows that $93.1 \%$ of physicians diagnose notified diseases. Half of all participants notify these diseases. Only $10.7 \%$ of participants had prior training on disease notification.

Table 4 shows that knowledge level was significantly associated with the participants' age, years of practice, degree and the department that they work on, being more in those who aged over 30 years, staff members and in those whose experience exceeds ten years. The level of attitude is significantly associated only with gender and department. The level of practice was significantly associated with age, the degree of physicians, department and years of practice.

Overall, Satisfactory knowledge, positive attitude and adequate practices scores were noted in $22.4 \%, 76.2 \%$, and $68.6 \%$ of participants respectively as shown in Figure 1.

The main reasons for non-reporting among those have never reported were: I don't know how or to whom to report $82.8 \%$, I don't know which diseases to report $72.8 \%$, I am too busy to report $71.5 \%$, lack of manpower $53.1 \%$ and I want to protect the patient privacy $46.4 \%$. 
Table 4: Relation between level of knowledge, attitude and practice of health care providers in Assuit University Hospitals and some personal and work variables

\begin{tabular}{|c|c|c|c|c|c|c|c|c|c|c|c|c|c|c|c|}
\hline & \multicolumn{4}{|c|}{ Level of knowledge } & \multirow{3}{*}{ P-value } & \multicolumn{4}{|c|}{ Level of attitude } & \multirow{3}{*}{ P-value } & \multicolumn{4}{|c|}{ Level of practice } & \multirow{3}{*}{ P-value } \\
\hline & \multicolumn{2}{|c|}{$\begin{array}{c}\text { Unsatisfactory } \\
(n=326)\end{array}$} & \multicolumn{2}{|c|}{$\begin{array}{c}\text { Satisfactory } \\
(n=94)\end{array}$} & & \multicolumn{2}{|c|}{$\begin{array}{l}\text { Negative } \\
(n=100)\end{array}$} & \multicolumn{2}{|c|}{$\begin{array}{l}\text { Positive } \\
(\mathrm{n}=320)\end{array}$} & & \multicolumn{2}{|c|}{$\begin{array}{l}\text { Negative } \\
(n=288)\end{array}$} & \multicolumn{2}{|c|}{$\begin{array}{l}\text { Positive } \\
(n=132)\end{array}$} & \\
\hline & No. & $\%$ & No. & $\%$ & & No. & $\%$ & No. & $\%$ & & No. & $\%$ & No. & $\%$ & \\
\hline \multicolumn{16}{|l|}{ Gender: } \\
\hline Male & 132 & 74.2 & 46 & 25.8 & \multirow{2}{*}{0.144} & 51 & 28.7 & 127 & 71.3 & \multirow{2}{*}{$0.046^{*}$} & 125 & 70.2 & 53 & 29.8 & \multirow[t]{2}{*}{0.531} \\
\hline Female & 194 & 80.2 & 48 & 19.8 & & 49 & 20.2 & 193 & 79.8 & & 163 & 67.4 & 79 & 32.6 & \\
\hline \multicolumn{15}{|l|}{ Age:(years) } & \multirow{4}{*}{$0.000 *$} \\
\hline$<30$ & 165 & 87.3 & 24 & 12.7 & \multirow{3}{*}{$0.000^{*}$} & 50 & 26.5 & 139 & 73.5 & \multirow{3}{*}{0.436} & 151 & 79.9 & 38 & 20.1 & \\
\hline $30-35$ & 106 & 81.5 & 24 & 18.5 & & 30 & 23.1 & 100 & 76.9 & & 95 & 73.1 & 35 & 26.9 & \\
\hline$>35$ & 55 & 54.5 & 46 & 45.5 & & 20 & 19.8 & 81 & 80.2 & & 42 & 41.6 & 59 & 58.4 & \\
\hline \multicolumn{16}{|l|}{ Position: } \\
\hline Physician & 264 & 76.1 & 83 & 23.9 & \multirow[b]{2}{*}{0.099} & 84 & 24.2 & 263 & 75.8 & \multirow[b]{2}{*}{0.676} & 241 & 69.5 & 106 & 30.5 & \multirow[t]{2}{*}{0.396} \\
\hline Head nurse & 62 & 84.9 & 11 & 15.1 & & 16 & 21.9 & 57 & 78.1 & & 47 & 64.4 & 26 & 35.6 & \\
\hline \multicolumn{16}{|c|}{ Degree of physician: } \\
\hline Resident & 140 & 89.2 & 17 & 10.8 & \multirow{4}{*}{$0.000 *$} & 43 & 27.4 & 114 & 72.6 & & 125 & 79.6 & 32 & 20.4 & \\
\hline Assistant & 89 & 80.9 & 21 & 19.1 & & 26 & 23.6 & 84 & 76.4 & 0.336 & 84 & 76.4 & 26 & 23.6 & \\
\hline lecturer & & & & & & & & & & & & & & & $0.000^{*}$ \\
\hline $\begin{array}{l}\begin{array}{l}\text { Staff } \\
\text { member }\end{array} \\
\end{array}$ & 35 & 43.8 & 45 & 56.3 & & 15 & 18.8 & 65 & 81.3 & & 32 & 40.0 & 48 & 60.0 & \\
\hline Department & & & & & & & & & & & & & & & \\
\hline $\begin{array}{l}\text { Internal } \\
\text { Medicine }\end{array}$ & 62 & 74.7 & 21 & 25.3 & & 21 & 25.3 & 62 & 74.7 & & 52 & 62.7 & 31 & 37.3 & \\
\hline $\begin{array}{l}\text { Children } \\
\text { Hospital }\end{array}$ & 94 & 80.3 & 23 & 19.7 & & 25 & 21.4 & 92 & 78.6 & & 96 & 82.1 & 21 & 17.9 & \\
\hline Women & & & & & & & & & & & & & & & \\
\hline $\begin{array}{l}\text { Health } \\
\text { Hospital }\end{array}$ & 57 & 89.1 & 7 & 10.9 & $0.002 *$ & 27 & 42.2 & 37 & 57.8 & $0.002 *$ & 53 & 82.8 & 11 & 17.2 & $0.000 *$ \\
\hline Clinical & & & & & & & & & & & & & & & 0.000 \\
\hline $\begin{array}{l}\text { Pathology } \\
\text { Department }\end{array}$ & 48 & 76.2 & 15 & 23.8 & & 8 & 12.7 & 55 & 87.3 & & 22 & 34.9 & 41 & 65.1 & \\
\hline $\begin{array}{l}\text { Chest } \\
\text { Department }\end{array}$ & 37 & 84.1 & 7 & 15.9 & & 12 & 27.3 & 32 & 72.7 & & 37 & 84.1 & 7 & 15.9 & \\
\hline $\begin{array}{l}\text { Tropical } \\
\text { Department }\end{array}$ & 28 & 57.1 & 21 & 42.9 & & 7 & 14.3 & 42 & 85.7 & & 28 & 57.1 & 21 & 42.9 & \\
\hline Years of expe & ence: & & & & & & & & & & & & & & \\
\hline$<5$ & 126 & 86.9 & 19 & 13.1 & & 40 & 27.6 & 105 & 72.4 & & 118 & 81.4 & 27 & 18.6 & \\
\hline $5-10$ & 123 & 81.5 & 28 & 18.5 & $0.000 *$ & 37 & 24.5 & 114 & 75.5 & 0.215 & 113 & 74.8 & 38 & 25.2 & $0.000 *$ \\
\hline$>10$ & 77 & 62.1 & 47 & 37.9 & & 23 & 18.5 & 101 & 81.5 & & 57 & 46.0 & 67 & 54.0 & \\
\hline
\end{tabular}




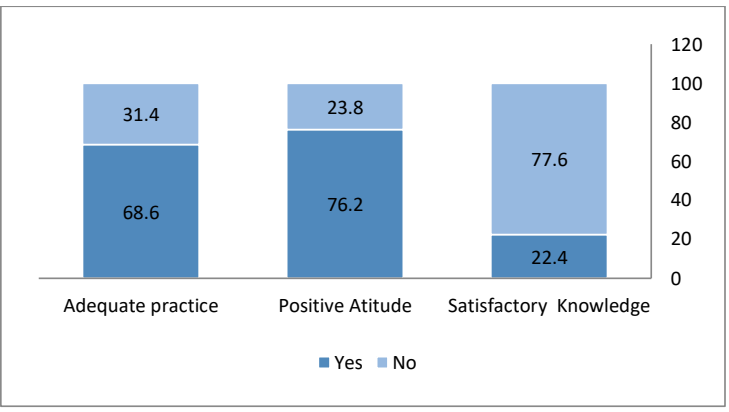

Figure 1: Score of knowledge, attitude and practice of health care providers in Assuit University Hospitals

\section{Discussion}

This study found that $(22.4 \%)$ of the participants have good level of knowledge about communicable diseases surveillance, that is better than a study conducted in Nigeria $^{13}$ where the percent was $(11.9 \%)$. Previous studies in other countries have found that the knowledge is generally poor $^{14,15,16}$ in Iran, Taiwan and India respectively. In a study conducted in the United States 2010, 55\% of physicians and $63 \%$ of nurses in emergency departments and primary health surveillance centers had adequate knowledge about reporting diseases. $^{17}$ Less than half of the participants were not aware of the presence of communicable diseases surveillance system in Assuit University Hospitals. This might be because the surveillance unit is newly established in 2014 and the health care providers sometimes report directly to the Assiut Directorate of Health and Population. In Nigeria a study was conducted in 2012 among health care workers found that $89.8 \%$ health-care workers were aware of the disease surveillance system. ${ }^{18}$

Regarding the function of disease surveillance $9.3 \%$ of the participants knew the four functions of surveillance system (as identified by the World Health Organization: data collection, analysis, dissemination, and application ${ }^{7}$ and this is much better than a study conducted on
Indian private practitioners, in which only $1 \%$ knew the four functions. ${ }^{16}$

Regarding the diseases included in surveillance system, about half of the participants knew correct answers about HIV and avian flu. This could be explained by the fact that these two diseases are obligatory notified to the ministry of health before the establishment of the surveillance unit of AUHS. The presence of case definition booklet was unknown to 93\% of participants, in which is comparable to the a study conducted in Germany on general practitioners 2001, where $86.5 \%$ don't know that there is a case definition booklet. ${ }^{19}$

Previous studies reported knowledge is not associated with physician's $\operatorname{sex}^{20,21}$ which matches the finding in the present study. The same two studies ${ }^{20,21}$ found that there is no association between years of practice and level of knowledge which doesn't match the finding in the present study.

Despite their limited knowledge and practice, the majority of the participants have a positive attitude. This attitude is encouraging because it signifies their willingness to participate in communicable diseases surveillance. Therefore it is imperative that the responsible authorities should use this positive attitude as a foundation for building capacity for healthcare workers. Efforts have to be made towards information dissemination regarding communicable diseases surveillance so that healthcare workers should be well equipped with knowledge.

The majority of the participants $87 \%$ agreed on the importance of disease surveillance for improving health .This is slightly less than the study conducted in India $^{16}$ showed that $93 \%$ of the participants agreed on that. The vast majority of the participants $92 \%$ agreed that reporting of communicable diseases is one of the responsibilities of the healthcare providers. 
This is matching the study conducted on private practitioners in Taiwan ${ }^{15}$ which was $99.2 \%$. In another study conducted in Saudi Arabia 91\% agreed that it is their responsibility to report ${ }^{22}$, and in $\operatorname{Iran}^{14} 76 \%$ of the participants agreed on this. Approximately two-thirds of the study participants agreed that a good reward system for reporting without punishment for non-reporting would increase the willingness to report. This is similar to the finding in previous study on urban private practitioners in India ${ }^{16}$ and a study in Saudi Arabia. $^{22}$

In the present study $43.1 \%$ of participants have been reporting infectious diseases, while in another study conducted among private and public primary health care workers in Nigeria it was $60.0 \% .{ }^{23}$ A study in Saudi Arabia's Jeddah region ${ }^{24}$ found a reporting rate of $74 \%$. The study shows that there is a moderate positive correlation between knowledge and practice that agreed with some previous studies in South Africa and United States. ${ }^{25,26}$ But this different from other study conducted in Taiwan ${ }^{15}$ that has found no association between knowledge of notified diseases and notified disease reporting.

The main reasons for non-reporting among those who have never reported, in this study, were: I don't know how or to whom I should report $73.1 \%$ This agreed with the study conducted in United States 2010,this reason was accepted in $55 \%$ of the participants. $^{27}$ In the present study $36.4 \%$ of the non-reporting participants referred the reasons of not reporting to the fact that the reporting process is complicated. This comes in accordance with a study conducted on pediatricians in Syrian Republic $30.6 \%$ of the participants agreed on this. ${ }^{28}$ Other reasons for not reporting communicable disease in this study was time constraint $71.5 \%$ and this is the most frequent cause identified by the participants in a study conducted in Saudi
Arabia $^{22}$ followed by confidentiality. In the present study, $46.4 \%$ also did not report communicable diseases because they want to protect patients privacy, while this is in other previous studies was less cited as a major barrier. ${ }^{28,21}$

\section{Conclusion}

More than half of the participants were not aware of the presence of communicable diseases surveillance system in AUHs. Most (three quarters) of the participants have a positive attitude about communicable diseases surveillance. Only one third of the participants have an adequate level of practice. The physicians have more satisfactory knowledge than head nurses although; head nurses have slightly more adequate practice than physicians. Regarding attitude, they are nearly equal. The main reasons for nonreporting were: lack of knowledge about how or to whom to report or which diseases to report and time constraint.

\section{Recommendations}

There should be regular awareness, information, education and communication programs concerning the surveillance system and its importance to the public, for health-care providers at all departments of the AUHS and on a regular basis too. This will help them appreciate the importance of the system and thus improve their general attitude towards it.

For data collection, there should be training and retraining programs for the health-care providers in the AUHS, and a nurse or a sanitarian in every department should be responsible for the collection of patients' registrations and notify the surveillance unit directly.

Case definitions booklets must be available for every doctor in all departments.

\section{References}

1. Kumar BA, Madhavi. KVP. Knowledge and practice regarding vector borne diseases 
among slum dwellers of Guntur district,Andhra Pradesh. J Evol Med Dent Sci [Internet]. 2013;2(1469):4756-62.

2. Kebede SS., Gatabazi JB. JB, Rugimbanya P. P, Mukankwiro T. T, Perry HNHN., Alemu W. W, et al. Strengthening systems for communicable disease surveillance: creating a laboratory network in Rwanda. Health Res Policy Syst [Internet]. 2011;9(1):27.

3. Doyle TJ, Glynn MK, Groseclose SL. Completeness of notifiable infectious disease reporting in the United States: An analytical literature review. Am J Epidemiol. 2002;155(9):866-74.

4. Tambo E, Ugwu EC, Ngogang JY. Need of surveillance response systems to combat Ebola outbreaks and other emerging infectious diseases in African countries Need of surveillance response systems to combat Ebola outbreaks and other emerging infectious diseases in African countries. 2014;

5. Kumar V, Raut D. History and evolution of surveillance in public health. Glob J Med Public Heal. 2014;3(1):7o.

6. Bartlett CL. The Communicable Disease Surveillance Centre 1977-2002: an overview. Commun Dis public Heal [Internet]. 2003 Jun [cited 2017 Oct 15];6(2):87-96.

7. World Health Organization (WHO). Communicable disease surveillance and response systems. 2014 . 2006;1-90.

8. Phalkey RK, Shukla S, Shardul S, Ashtekar $\mathrm{N}$, Valsa S, Awate P, et al. Assessment of the core and support functions of the Integrated Disease Surveillance system in Maharashtra, India. BMC Public Health [Internet]. 2013;13(1):575.

9. Nnebue $\mathrm{CC}$, Onwasigwe $\mathrm{CN}$, Ibeh $\mathrm{CC}$, Adogu POU. Effectiveness of data collection and information transmission process for disease notification in anambra state, Nigeria. Niger J Clin Pract. 2013;16(4):483-9.

10. World Health Organization. Communicable disease surveillance and response systems - Guide to monitoring and evaluating. Epidemic and pandemic alert and response [Internet]. 2006;90.

11. Lederberg J, Oaks SC. Sua 14. 1992;298.

12. CJ S, PH G, Allison M, Mottice S, Rubin M, JH S, et al. Urgent care providers' knowledge and attitude about public health reporting and pertussis control measures: implications for informatics. J Public Heal Manag Pract [Internet]. 2009;15(6):471-8. 13. Ofili AN, Ugwu EN, Ziregbe A, Richards $\mathrm{R}$, Salami S. Knowledge of disease notification among doctors in government hospitals in Benin Ciy, Edo State, Nigeria. Public Health. 2003;117(3):214-7.

14. Nader F, Askarian M. How do Iranian physicians report notifiable diseases? The first report from Iran. Am J Infect Control [Internet]. 2009;37(6):500-4.

15. Tan H-F, Yeh C-Y, Chang H-W, Chang C$\mathrm{K}$, Tseng H-F. Private doctors' practices, knowledge, and attitude to reporting of communicable diseases: a national survey in Taiwan. BMC Infect Dis [Internet]. 2009;9(1):11.

16. Phalkey RK, Kroll M, Dutta S, Shukla S, Butsch C, Bharucha E, et al. Knowledge, attitude, and practices with respect to disease surveillance among urban private practitioners in Pune, India. Vol. 8, Global Health Action. 2015.

17. Turnberg W, Daniell W, Duchin J. Notifiable infectious disease reporting awareness among physicians and registered nurses in primary care and emergency department settings. Am J Infect Control [Internet]. 2010;38(5):410-2.

18. Nnebue C, Onwasigwe C, Onyeonoro U, Adogu PU. Awareness and knowledge of disease surveillance and notification by healthcare workers and availability of facility records in Anambra state, Nigeria. Niger Med J [Internet]. 2012;53(4):220.

19. Krause G, Ropers G, Stark K. Notifiable disease surveillance and practicing physicians [Internet]. Vol. 11, Emerging Infectious Diseases. Centers for Disease Control and Prevention; 2005 [cited 2017 Aug 13]. p. 4425.

20. Durrheim DN, Thomas J. General practice awareness of notifiable infectiousdiseases. Public Health. 1994;108(4):273-8.

21. Friedman SM, Sommersall LA, Gardam M, Arenovich T. Suboptimal reporting of notifiable diseases in Canadian emergency departments: a survey of emergency physician knowledge, practices, and perceived barriers. 
Can Commun Dis Rep. 2006;32(17):187-98. 22. Mansuri FA, Borhany T, Kalar M. Factors responsible for under reporting of notifiable infectious diseases by general practitioners: A veiled reality. Biomedica. 2014;30(2):126-9. 23. Chikee Aniwada E, Obionu CN. Disease Surveillance and Notification, Knowledge and Practice among Private and Public Primary Health Care Workers in Enugu State, Nigeria: A Comparative Study. Br J Med Med Res [Internet]. 2016;13(133):1-10.

24. Bakarman MA, Al-raddadi RM. Assessment of reporting and recording system of communicable diseases in Jeddah Region. 2000;966(April):751-4.

25. Durrheim DN, Harris BN, Speare R, Billinghurst $\mathrm{K}$. The use of hospital-based nurses for the surveillance of potential disease outbreaks. Bull World Health Organ.
2001;79(1):22-7.

26. Figueiras A, Lado E, Fernández S, Hervada X. Influence of physicians' attitudes on under-notifying infectious diseases: A longitudinal study. Public Health. 2004;118(7):521-6.

27. Revere D, Hills RH, Dixon BE, Gibson PJ, Grannis SJ. Notifiable condition reporting practices: Implications for public health agency participation in a health information exchange. BMC Public Health. 2017;17(1):112.

28. Al-Laham H, Khoury R, Bashour $\mathrm{H}$. Reasons for underreporting of notifiable diseases bSyrian paediatricians. East Mediterr Heal journal= La Rev sante la Mediterr Orient al-Majallah al-sihhiyah li-sharq al-mutawassit. 2001;7(4-5):590-6. 